\title{
Long-term prognosis for infants with intrahepatic cholestasis and patent extrahepatic biliary tract
}

\author{
M ODIĖVRE, M HADCHOUEL, P LANDRIEU, D ALAGILLE, AND N ELIOT \\ Unité de Recherche d'Hépatologie Infantile, INSERM U 56, and Clinique de Pédiatrie, Université Paris-Sud, \\ Hôpital d'Enfants, France
}

SUMMARY One hundred and three infants with prolonged cholestasis beginning before age 3 months were classified as having $\alpha$-1-antitrypsin deficiency (17 patients), scanty interlobular bile ducts (16 patients), or 'neonatal hepatitis' (70 patients). Twenty-two gradually developed chronic liver disease and the remaining 81 recovered within a few months. Prognosis was found to be poor for infants with $\alpha$-1-antitrypsin deficiency, scanty interlobular bile ducts, and familial 'idiopathic' hepatitis. Patients who developed cirrhosis often presented with severe and persistent neonatal cholestasis, mimicking extrahepatic biliary atresia and leading to laparotomy. Thus, a high-risk group of infants - defined by aetiology, family history, and degree of cholestasis — can be recognised in the first months of life.

Most infants with prolonged cholestasis have either extrahepatic biliary atresia or intrahepatic disease. The prognosis for those with the latter is not clear; some factors-such as aetiology, ${ }^{12}$ familial occurrence, ${ }^{34}$ presence of a second disease 4 -have been claimed to affect the prognosis adversely. Progression to cirrhosis has also been observed in patients having undergone laparotomy and general anaesthesia ${ }^{5}$ because extrahepatic biliary atresia, a condition not always distinguishable from neonatal hepatitis, must be operated on as soon as possible, ${ }^{6}$ even though this means a large number of patients may be subjected to surgery.

Our study aims to define which factors influence the long term-prognosis for infants with intrahepatic cholestasis and patent extrahepatic biliary tract.

\section{Patients}

One hundred and three children ( 70 boys and 33 girls) with prolonged cholestasis beginning before age 3 months $^{7}$ were studied from 1964 to 1974 . Age at admission ranged from one week to 6 months.

Patency of the extrahepatic biliary tract was deduced by spontaneous clearing of jaundice in 72 patients; it was proved by laparotomy in the remaining 31 . Surgery was carried out at a mean age of 3 months by the same surgeon without any major modification of anaesthetic procedures during the period of the study. In each case laparotomy was associated with cholangiography and wedge liver biopsy.
The 103 cases were classified as follows:

Alpha-1-antitrypsin deficiency $(n=17)$ demonstrated by low serum concentration and PiZ phenotype; in one patient, only a retrospective diagnosis was possible, made after reviewing the liver histology.

Sparse interlobular bile ducts $(n=16)$ assessed from the study of serial liver biopsies. Three of these children had multiple developmental abnormalities too. ${ }^{8}$

'Neonatal hepatitis' $(n=70)$.

Virus isolation studies and serological tests were not performed in all patients. Four out of 54 tested were positive for rubella, 1 out of 53 for toxoplasmosis, none out of 52 for syphilis, 3 out of $\mathbf{4 9}$ for HBsAg, 3 out of 42 for cytomegalovirus, and none out of $\mathbf{8}$ for herpes virus infection.

The surviving infants were followed up for a minimum of 2 and a maximum of 13 years. All survivors were re-examined recently for this study.

\section{Methods}

Children were classified on the basis of long-term outcome according to serial clinical, biochemical, and histological investigations. Group 1 comprised patients who gradually developed chronic liver disease, as shown by hepatomegaly with or without splenomegaly, collateral abdominal veins, ascites, and permanent or recurrent cholestasis. Group 2 comprised the remaining patients, who recovered within a few months. 
The initial data (Tables 1 and 2) were compared in both groups. The relationship between outcome and surgery was analysed in a similar manner. Finally, correlations between long-term prognosis and aetiology of cholestasis were sought. All data were analysed by a computer.

\section{Results}

There were 22 patients in group 1 and 81 in group 2 . Fourteen patients in group 1 died aged between 6 months and 7 years from liver damage.

Data and long-term outcome (Table 1). Patients in group 1 had an appreciably higher percentage of siblings also affected with neonatal cholestasis: 7 sibships were affected in this group compared with 4 sibships in group 2 . The children in group 1 also had later onset of pale stools and their livers were more often hard. Transaminase activity on admission was higher. A feature in this group was the greater number of patients in whom liver biopsy demonstrated bile duct proliferation and portal fibrosis.

Data and diagnostic laparotomy (Table 2). In patients who were operated on, permanently pale stools and hard livers were more often noted than in those who were not. The preoperative histological data were also very different: bile duct proliferation and portal fibrosis were more frequently observed in patients who underwent surgery.

Table 1 Relationship between initial data and long-term outcome

\begin{tabular}{|c|c|c|c|}
\hline & $\begin{array}{l}\text { Group } I^{*} \\
(n=22)\end{array}$ & $\begin{array}{l}\text { Group 2† } \\
(n=81)\end{array}$ & \\
\hline Sex: male/female $\times 100$ & $66 \cdot 7$ & $68 \cdot 6$ & NS \\
\hline Mean birthweight (g) & $2702 \pm 51$ & $2787 \pm 10$ & NS \\
\hline Affected siblings $(\%)$ & & & $P<0.001$ \\
\hline $\begin{array}{l}\text { Age at onset of jaundice } \\
\text { (days) }\end{array}$ & $25 \pm 3$ & $23 \pm 2$ & NS \\
\hline Age at onset of pale stools & & & \\
\hline $\begin{array}{l}\text { (days) } \\
\text { Permanently }\end{array}$ & $47 \pm 6$ & $27 \pm 2$ & $P<0.03$ \\
\hline Permanently pale stools $(\%)$ & $41 \cdot 7$ & $29 \cdot 0$ & NS \\
\hline \multicolumn{4}{|l|}{ At admission } \\
\hline Hard liver $(\%)$ & $27 \cdot 0$ & $5 \cdot 0$ & $P<0.01$ \\
\hline Splenomegaly (\%) & $62 \cdot 5$ & $45 \cdot 6$ & NS \\
\hline $\begin{array}{l}\text { Bilirubin } \\
\quad(\mathrm{mg} / 100 \mathrm{ml})\end{array}$ & $9 \cdot 1 \pm 0 \cdot 7$ & $8 \cdot 2 \pm 0 \cdot 6$ & NS \\
\hline Cholesterol & & & \\
\hline$(\mathrm{mg} / 100 \mathrm{ml})$ & $260 \pm 70$ & $260 \pm 90$ & NS \\
\hline $\begin{array}{l}\text { Serum proteins }(\mathrm{g} / 100 \mathrm{ml}) \\
\text { Abnormal glutamic }\end{array}$ & $6 \cdot 6 \pm 0 \cdot 7$ & $6 \cdot 4 \pm 0.9$ & NS \\
\hline transaminase activity $(\%)$ & $30 \cdot 4$ & $16 \cdot 4$ & $P<0.05$ \\
\hline Bile duct proliferation ( $\%$ ) & $33 \cdot 3$ & $13 \cdot 4$ & $\mathbf{P}<\mathbf{0 . 0 0 1}$ \\
\hline Portal fibrosis ( $\%)$ & $60 \cdot 0$ & $22 \cdot 6$ & $P<0.001$ \\
\hline
\end{tabular}

*Group 1 developed chronic disease, tgroup 2 recovered. NS = not significant.

Conversion: traditional to $S I$ units-bilirubin: $1 \mathrm{mg} / 100 \mathrm{ml} \approx 17 \cdot 1$ $\mu \mathrm{mol} / \mathrm{l}$; cholesterol: $1 \mathrm{mg} / 100 \mathrm{ml} \approx 0.0259 \mu \mathrm{mol} / 1$.
Table 2 Relationship between initial data and diagnostic laparotomy

\begin{tabular}{|c|c|c|c|}
\hline & $\begin{array}{l}\text { Non operated } \\
(n=72)\end{array}$ & $\begin{array}{l}\text { Operated } \\
(n=31)\end{array}$ & \\
\hline Sex: male $/$ female $\times 100$ & $66 \cdot 6$ & $70 \cdot 9$ & NS \\
\hline Mean birthweight (g) & $2686 \pm 69$ & $2722 \pm 57$ & NS \\
\hline Affected siblings ( $\%)$ & $6 \cdot 9$ & $19 \cdot 3$ & NS \\
\hline Age at onset of jaundice & & & \\
\hline (days) & $22 \pm 2$ & $24 \pm 2$ & NS \\
\hline Age at onset of pale stools & & & \\
\hline (days) & $32 \pm 4$ & $31 \pm 3$ & NS \\
\hline Permanently pale stools $(\%)$ & $25 \cdot 0$ & $48 \cdot 4$ & $\mathrm{P}<0.02$ \\
\hline \multicolumn{4}{|l|}{ At admission } \\
\hline Hard liver (\%) & $5 \cdot 5$ & $19 \cdot 4$ & $P<0.05$ \\
\hline Splenomegaly $(\%)$ & $51 \cdot 4$ & $45 \cdot 2$ & NS \\
\hline \multicolumn{4}{|l|}{ Bilirubin } \\
\hline$(\mathrm{mg} / 100 \mathrm{ml})$ & $7.9 \pm 0.6$ & $9 \cdot 5 \pm 0.6$ & NS \\
\hline \multicolumn{4}{|l|}{ Cholesterol } \\
\hline$(\mathrm{mg} / 100 \mathrm{ml})$ & $250 \pm 10$ & $270 \pm 10$ NS & \\
\hline Serum proteins $(\mathrm{g} / 100 \mathrm{ml})$ & $6.4 \pm 0.08$ & $6.67 \pm 0.07$ & NS \\
\hline \multicolumn{4}{|c|}{ Abnormal glutamic } \\
\hline transaminase activity $(\%)$ & $18 \cdot 5$ & $22 \cdot 6$ & NS \\
\hline Bile duct proliferation $(\%)$ & $3 \cdot 8$ & $34 \cdot 0$ & $P<0.001$ \\
\hline Portal fibrosis (\%) & $20 \cdot 3$ & $51 \cdot 0$ & $P<0.001$ \\
\hline
\end{tabular}

Relationship between diagnostic laparotomy and long-term outcome (Fig. 1). Diagnostic laparotomy was significantly related to long-term outcome: 14 of the 22 children who developed chronic liver disease had undergone surgery compared with 17 of the 81 children who recovered $(P<0 \cdot 001)$.

Aetiological factors (Table 3). Among the 7 patients with $\alpha$-1-antitrypsin deficiency who developed chronic liver disease, 5 had undergone exploratory laparotomy and none had affected siblings.

Five patients with scanty interlobular bile ducts also developed cirrhosis; four of them were operated

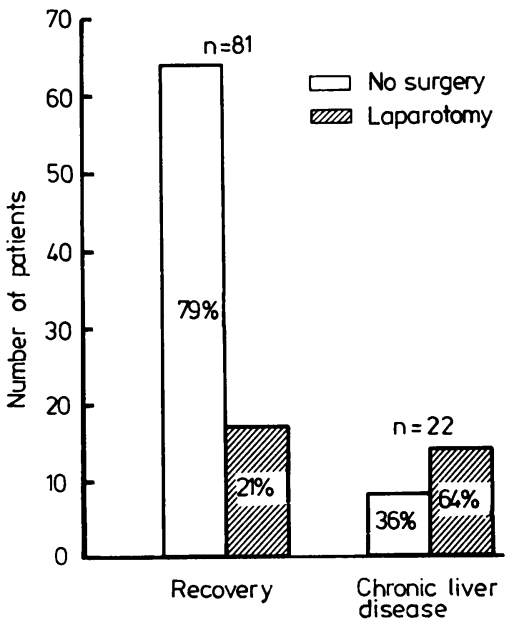

Fig. 1 Relationship between diagnostic laparotomy and long-term outcome. 
Table 3 Aetiological categories of intrahepatic cholestasis and outcome

\begin{tabular}{|c|c|c|c|c|c|c|}
\hline \multirow[t]{3}{*}{ Aetiological categories } & \multirow{3}{*}{$\begin{array}{l}\text { No of } \\
\text { patients } \\
(n=103)\end{array}$} & \multicolumn{2}{|c|}{ Laparotomy } & \multicolumn{3}{|c|}{ Long-term outcome } \\
\hline & & \multirow[t]{2}{*}{ Yes } & \multirow[t]{2}{*}{ No } & \multirow[t]{2}{*}{ Recovery } & \multicolumn{2}{|c|}{ Chronic liver disease } \\
\hline & & & & & Living & Dead \\
\hline $\begin{array}{l}\text { Alpha-1-antitrypsin deficiency } \\
\text { Scanty interlobular bile ducts } \\
\text { 'Idiopathic' cholestasis }\end{array}$ & $\begin{array}{l}17 \\
16 \\
70\end{array}$ & $\begin{array}{r}7 \\
14 \\
10\end{array}$ & $\begin{array}{r}10 \\
2 \\
60\end{array}$ & $\begin{array}{l}10 \\
11 \\
60\end{array}$ & $\begin{array}{l}5 \\
2 \\
1\end{array}$ & $\begin{array}{l}2 \\
3 \\
9\end{array}$ \\
\hline
\end{tabular}

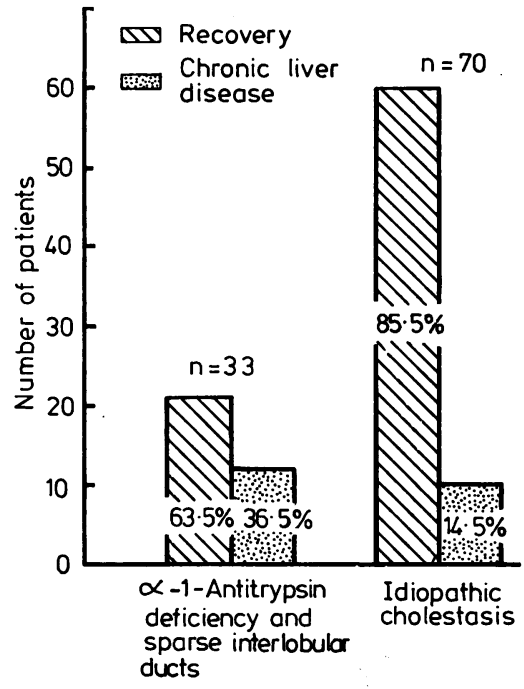

Fig. 2 Relationship between aetiological factors and long-term outcome.

on. One child had one affected sibling, not included in this study, who died with cirrhosis.

Cholestasis was considered idiopathic in 70 patients although viral isolation and positive serological studies were obtained in 11 . Ten of the 70 patients developed severe chronic liver disease which led to death in 9; familial occurrence was present in 6 of these 10 patients: 2 sibships with 2 affected children included in this series, and 2 other sibships in which 2 children were known to have died from cirrhosis. Despite these figures, 'idiopathic' cholestasis appeared to be associated with more favourable prognosis (Fig. 2). The few patients with viral isolation and positive serological studies recovered spontaneously.

\section{Discussion}

Many studies have shown that a significant percentage of infants with neonatal hepatitis develop chronic liver disease. ${ }^{3-5}$ Our results confirm this, since $21 \%$ of patients with intrahepatic cholestasis and patent extrahepatic biliary tract developed cirrhosis with $63 \%$ mortality. However, the term 'neonatal hepatitis' may represent several distinct entities ${ }^{9}$ and the prognosis may depend on a variety of factors.

Aetiology may be important in this respect. Seven of the 13 babies in whom progressive liver disease developed presented with a second factor $(\alpha-1$ antitrypsin deficiency, Aagenaes's syndrome, postnatal cytomegalovirus infection, Niemann-Pick disease, or polycystic kidneys) but it was not clear whether all these patients had persistent obstructive jaundice. ${ }^{4}$ In our study, the association of $\alpha-1$ antitrypsin deficiency, a well-known cause of cirrhosis in children, correlated well with poor prognosis; serious portal fibrosis and bile duct proliferation during the neonatal cholestatic stage have been seen in babies with further development of cirrhosis. ${ }^{10} 11$

Progression to cirrhosis is also common in patients with sparse interlobular ducts, a finding which has been reported previously. ${ }^{12} 13$ Early diagnosis of this condition is difficult; serial liver biopsies are required since small and medium-sized bile ducts may appear to diminish in number or disappear.

The potentially adverse role of a family history has been outlined. ${ }^{34}$ This role has been refuted by a new analysis of earlier data, showing that cirrhosis was more common in infants undergoing surgery, regardless of whether they were categorised as sporadic or familial. ${ }^{14}$ In our series of patients, familial incidence was high only in those patients with 'idiopathic' cholestasis who developed cirrhosis. Whether these patients had recessively inherited disorders such as Aagenaes's or Byler's disease is not known in the absence of lymphoedema ${ }^{15}$ on the one hand, and the lack of specific criteria for Byler's disease on the other.

It has been claimed that laparotomy leads to a worse prognosis. ${ }^{16}$ Therefore it has been suggested that surgery in children with neonatal cholestasis should be delayed until the 4th month of life (assuming that many infants with neonatal hepatitis would recover spontaneously by this age). In our series, progression to cirrhosis was observed mainly 
in patients who had undergone surgery. However, several reports suggest that there is no higher incidence of chronic liver disease in infants with neonatal hepatitis who undergo surgery. ${ }^{317}$ In fact, the potentially adverse role of laparotomy must be judged with respect to the severity of the liver disease. Thus, the patients who were operated on were indistinguishable, according to the criteria used in selection for surgery, from those who were managed medically. ${ }^{16}$ In another series poor prognosis was mainly observed in patients with neonatal hepatitis mimicking extrahepatic biliary atresia. ${ }^{4}$ Our study shows that the majority of patients who were subjected to surgery had permanently pale stools, hard livers, and histological features suggesting mechanical bile duct obstruction.

In conclusion, the long-term prognosis for infants with intrahepatic cholestasis and patent extrahepatic biliary tract seems to be related to factors which can be recognised in the first stage of the disease. It is worse with $\alpha$-1-antitrypsin deficiency, scanty interlobular ducts, and in familial 'idiopathic' cholestasis. Children with severe cholestasis, as severe as that observed in biliary atresia who have laparotomy, are also likely to develop chronic liver disease.

\section{References}

1 Mowat A P, Psacharopoulos H T, Williams R. Extrahepatic biliary atresia versus neonatal hepatitis. Review of 137 prospectively investigated infants. Arch Dis Child 1976; 51 : 763-70.

2 Danks D M, Campbell P E, Jack I, Rogers J, Smith A L. Studies of the aetiology of neonatal hepatitis and biliary atresia. Arch Dis Child 1977; 52:360-7.

${ }^{3}$ Lawson E E, Boggs J D. Long-term follow-up of neonatal hepatitis: safety and value of surgical exploration. Pediatrics 1974; 53 : 650-5.

4 Danks D M, Campbell P E, Smith A L, Rogers J. Prognosis of babies with neonatal hepatitis. Arch Dis Child 1977; 52: 368-72.

5 Thaler M M, Gellis S S. Studies in neonatal hepatitis and biliary atresia. I. Long-term prognosis of neonatal hepatitis. Am J Dis Child 1968; 116: 257-61.
6 Kasai M, Kimura S, Asakura Y, Suzuki H, Taira Y, Ohashi E. Surgical treatment of biliary atresia. J Pediatr Surg 1968; 3: 665-75.

7 Eliot N, Odièvre, M Hadchouel M, Hill C, Flamant R. Analyse statistique des données cliniques, biologiques, et histologiques dans 288 observations de cholestase néonatale. Arch Fr Pediatr 1977; 34: Supplement 2, 213-20.

8 Alagille D, Odièvre $M$, Gautier $M$, Dommergues $J$ P. Hepatic ductular hypoplasia associated with characteristic facies, vertebral malformations, retarded physical, mental, and sexual development, and cardiac murmur. $J$ Pediatr 1975; 86: 63-71.

9 Thaler M M. Cryptogenic liver disease in young infants. In: Popper H, Shaffner F, eds. Progress in liver diseases. Vol. 5. New York: Grune \& Stratton, 1976: 476.

10 Hadchouel M, Gautier M. Histopathologic study of the liver in the early cholestatic phase of alpha-1-antitrypsin deficiency. J Pediatr 1976; 89: 211-5.

11 Psacharopoulos H T, Mowat A P, Portmann B T, Williams $R$. The prognosis in childhood of liver disease associated with alpha-1-antitrypsin deficiency (PiZZ). In: Japanese Medical Research Foundation, eds. Cholestasis in infancy. Its pathogenesis, diagnosis, and treatment. Tokyo: University of Tokyo Press, 1980: 133-40.

12 Heathcote J, Deodhar K P, Scheuer P J, Sherlock S. Intrahepatic cholestasis in childhood. $N$ Engl J Med 1976; 295: 801-5.

13 Alagille D, Odièvre M. Liver and biliary tract disease in children. New York: Wiley, 1979: 86.

14 Thaler M M. Letter: Questions regarding neonatal hepatitis. Pediatrics 1975; 55:296-7.

15 Aagenaes O, Sigstad H, Bjørn-Hansen R. Lymphoedema in hereditary recurrent cholestasis from birth. Arch Dis Child 1970; 45: 690-5.

16 Thaler M M, Gellis S S. Studies in neonatal hepatitis and biliary atresia. II. The effect of diagnostic laparotomy on long-term prognosis of neonatal hepatitis. Am J Dis Child 1968 ; 116: 262-70.

17 Grand R J, Watkins J B, Katz A J, Lawson E E. Letter: Neonatal jaundice: recent developments. $N$ Engl J Med 1975; 292 : 1028.

Correspondence to Dr M Odièvre, Hôpital d'Enfants de Bicêtre, 78 rue du Général-Leclerc, 94270 Bicêtre, France.

Received 8 January 1980 